\title{
Theoretical Studies on Photoisomerizations of (6-4) and Dewar Photolesions in DNA
}

\author{
Yue-Jie Ai, ${ }^{\dagger, *}$ Rong-zhen Liao, ${ }^{\dagger, \S}$ Shu-feng Chen, ${ }^{\dagger}$ Yi Luo, ${ }^{*, \dagger}$ and Wei-Hai Fang*, ${ }^{*}$ \\ College of Chemistry, Beijing Normal University, Beijing 100875, China, Theoretical Chemistry, School of \\ Biotechnology, Royal Institute of Technology, S-10691 Stockholm, Sweden, and Department of Organic \\ Chemistry, Arrhenius Laboratory, Stockholm University, S-10691 Stockholm, Sweden
}

Received: August 19, 2010; Revised Manuscript Received: October 5, 2010

\begin{abstract}
The (6-4) photoproduct ((6-4) PP) is one of the main lesions in UV-induced DNA damage. The (6-4) PP and its valence isomer Dewar photoproduct (Dewar PP) can have a great threat of mutation and cancer but gained much less attention to date. In this study, with density functional theory (DFT) and the complete active space self-consistent field (CASSCF) methods, the photoisomerization processes between the (6-4) PP and the Dewar PP in the gas phase, the aqueous solution, and the photolyase have been carefully examined. Noticeably, the solvent effect is treated with the CASPT2//CASSCF/Amber (QM/MM) method. Our calculations show that the conical intersection $(\mathrm{CI})$ points play a crucial role in the photoisomerization reaction between the (6-4) PP and the Dewar PP in the gas and the aqueous solution. The ultrafast internal conversion between the $S_{2}\left({ }^{1} \pi \pi^{*}\right)$ and the $S_{0}$ states via a distorted intersection point is found to be responsible for the formation of the Dewar PP lesion at $313 \mathrm{~nm}$, as observed experimentally. For the reversed isomeric process, two channels involving the "dark" excited states have been identified. In addition to the above passages, in the photolyase, a new electron-injection isomerization process as an efficient way for the photorepair of the Dewar PP is revealed.
\end{abstract}

\section{Introduction}

UV radiation can cause photodamage to DNA and eventually give rise to mutations, leading to damaging biological consequences, like skin cancer. ${ }^{1-6}$ The absorption of the UV light by DNA results in mainly two reactive photochemical lesions: cyclobutane pyrimidine dimers (CPDs) and pyrimidine (6-4) pyrimidone $((6-4) \mathrm{PP}))^{7,8}$ The latter lesion can be further transferred to its Dewar valence photoisomer, the so-called Dewar PP. ${ }^{9}$ (Scheme 1) It is generally believed that the mutagenic and carcinogenic threat of UV photodamage comes mainly from CPDs. ${ }^{10,11}$ The formation and repair mechanisms of CPDs have been extensively studied both experimentally and theoretically. ${ }^{7}$ In contrast, much less is known about the $(6-4)$ $\mathrm{PP}$ and its isomerization process. Recent studies found that 6-4PP lesions were more toxic and mutagenic compared with CPDs in nucleotide excision repair (NER)-deficient cells and made it currently a subject of intensive studies. ${ }^{10,12}$ The (6-4) PP arises from the linkage between the C6 of one pyrimidine and the $\mathrm{C} 4$ of the adjacent pyrimidine, as shown in Scheme 1. It is the product from a Paterno-Büchi reaction after ringopening of an oxetane intermediate..$^{13}$ When exposed to UV-B light $(313-280 \mathrm{~nm})$, the photoisomeration of the (6-4) PP produces its valence isomers-the Dewar PP and can be reconverted to the (6-4) PP at $240 \mathrm{~nm} \cdot{ }^{14}$ Because of the low yield and the difficulties in detecting, there were only a few reports on the Dewar PP to date. Perdiz et al. reported the relatively high production of the Dewar PP by simulated solar light and proposed that the Dewar PP may be a biologically relevant photolesion..$^{15}$ Very recently, Glas et al. reported that the repair of Dewar valence isomers by (6-4) photolyase

* To whom correspondence should be addressed. E-mail: luo@kth.se (Y.L.); fangwh@bnu.edu.cn (W.-H.F.).

${ }^{\dagger}$ Beijing Normal University.

* Royal Institute of Technology.

${ }^{\S}$ Stockholm University.

\section{SCHEME 1}

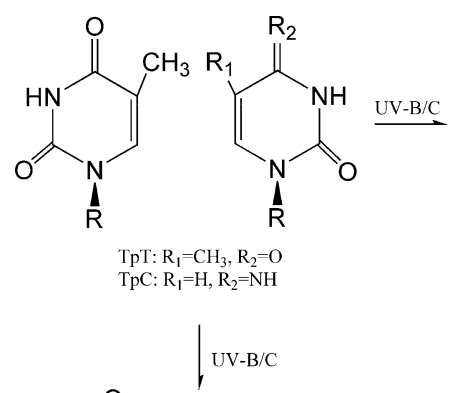

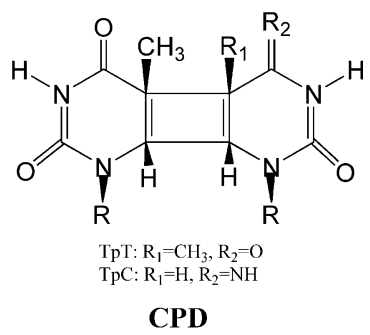

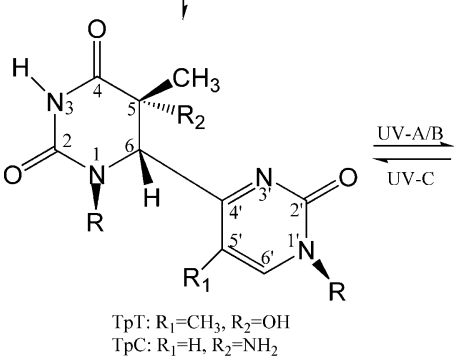

(6-4)PP

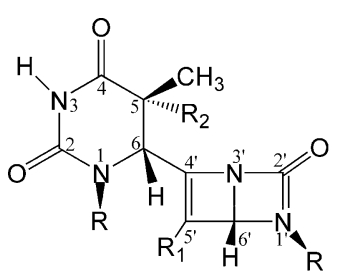

TpT: $\mathrm{R}_{1}=\mathrm{CH}_{3}, \mathrm{R}_{2}=\mathrm{OH}$ TpC: $\mathrm{R}_{1}=\mathrm{H}, \mathrm{R}_{2}=\mathrm{NH}_{2}$

DewarPP involved a rearrangement of the Dewar lesions into the corresponding (6-4) lesions. ${ }^{16}$ All of these studies clearly demonstrate that the (6-4) PP and the Dewar PP are neither quantitatively nor biologically negligible.

More work on these systems is thus highly desirable. There are several fundamental issues that need to be elucidated. These include the formation mechanism of the Dewar PP, the isomerization mechanism to the (6-4) PP, the impact of a biological environment (like solvent effect or enzyme catalysis) on the isomerization processes, and the photorepair mechanism of the (6-4) and Dewar photolesions. To address the above issues, the first thing that one needs to have is the basic structural information of these two photolesions. In this work, we have 


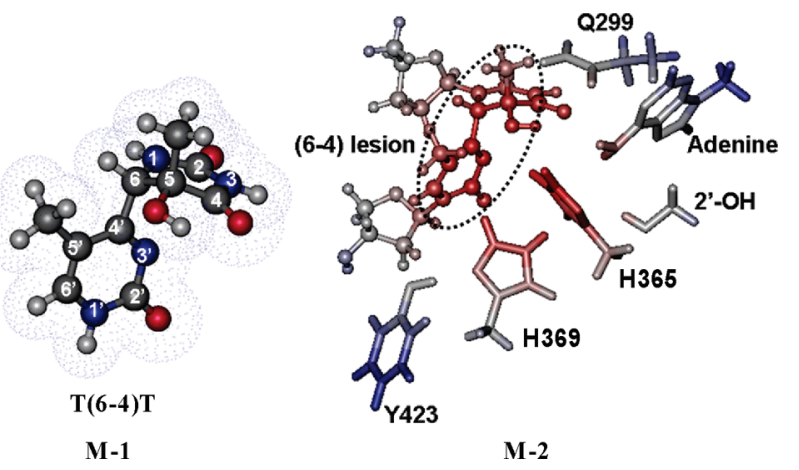

Figure 1. Structures and labeling of two computational models: the M-1(small model with only two bases) and the M-2 (large model including surrounding important residues).

employed ab initio computational methods to determine the geometric and electronic structures of the (6-4) PP and the Dewar PP as well as the photoinduced isomerization processes between them. The general pictures obtained from our theoretical calculations are very useful for the understanding of the photodamage and the even the following photorepair processes of DNA.

\section{Computational Methods}

Initial geometries of the (6-4) PP and the Dewar PP are taken from crystal structures (PDB codes: 1CFL and $1 \mathrm{QKG}){ }^{17}$ For our purpose, a simple model "M-1" is constructed; see Figure 1 , which contains only two thymine bases. To explore the isomerization reaction in the photolyase where a radical anion (RA) can be formed by the electron injection from the cofactor, the surrounding residues are added to the model "M-1" to form the model "M-2", as shown also in Figure 1.

All stationary and transition structures of the ground and excited states of the M-1 model were optimized using the complete active space self-consistent field (CASSCF) method. Because the main reaction coordinate lies on one ring of the 2 pyrimidines, 10 electrons and 8 molecular orbitals as the active space, labeled as $\mathrm{CAS}(10,8)$, was used. The active space includes six bonding and antibonding $\pi$ orbitals and two $\sigma$-MOs of the pyrimidone ring. We verified the minima and transition states (TSs) by calculating harmonic vibrational frequencies along the reaction path. To obtain more reliable total energies, we included the effects of dynamic electron correlation by performing CASPT2 calculations at the optimized CASSCF geometries. For the M-2, because of the computational limitation, the B3LYP and UB3LYP were employed to calculate the singlet neutral and RA molecules, respectively.

To mimic the aqueous environment of the photoproducts, we built a water solvent box positioned within $8 \AA$ of the M-1 molecule using the xleap module of the Amber ${ }^{18}$ software package. Then, the CASPT2//CASSCF/Amber (QM/MM) protocol was used to compute the potential energy surface of the photochemical steps in the aqueous solution. For the M-2, the solvent effect was considered with a polarizable continuum model (IEF-PCM). ${ }^{19-21}$ A dielectric constant of 4 was used to model the parts of the enzyme that are not included in the quantum chemical active site model. ${ }^{22-28}$

A standard 6-31G(d) basis set was used throughout the calculations. All CASSCF and CASPT2 calculations were performed by the Gaussian software package ${ }^{29}$ and MOLCAS ${ }^{30}$ programs. The Amber force field (MM subsystem) was treated by the Tinker ${ }^{31}$ tool packages. The interface between the QM and MM subsystems was coded by Ferré and coworkers ${ }^{32}$ and commercialized together with the MOLCAS program. All structural figures were drawn with the molecular visualization program VMD. ${ }^{33}$

\section{Results and Discussion}

Photoinduced Isomerization between the (6-4) PP and the Dewar PP in the Gas Phase. The photoinduced isomerization of the (6-4) PP was first observed by Johns in $1964 .{ }^{14}$ It was shown that the (6-4) product could convert quantitatively to a new photoproduct (the Dewar PP) at $313 \mathrm{~nm}$ and then back again at $240 \mathrm{~nm} \cdot{ }^{14}$ However, there are no related theoretical reports on this photoisomerization. We first study here the isomerization of the $\mathrm{T}(6-4) \mathrm{T}$ (pyrimidine (6-4) pyrimidone) and the $\mathrm{T}(\mathrm{dew}) \mathrm{T}$ (thymidylyl $\left(3^{\prime} \rightarrow 5^{\prime}\right)$ thymidine) in the gas phase. The optimized geometries of the $\mathrm{T}(6-4) \mathrm{T}$ and the $\mathrm{T}(\mathrm{dew}) \mathrm{T}$ in the ground and excited states from CAS(10,8)/6-31G(d) calculations are displayed in Figures 2 and 3, respectively. The corresponding total energies obtained from CASSCF/CASPT2 calculations are summarized in Table 1.

For the $\mathrm{T}(6-4) \mathrm{T}$, the pyrimidone ring at the $\mathrm{T}_{1}$ state is noticeably expanded in comparison with that of the $\mathrm{S}_{0}$. The $\mathrm{C}^{\prime}-\mathrm{H}$ bends out of the ring plane. The $\mathrm{T}_{1}$ state is $2.9 \mathrm{eV}$ at CASPT2 level above the $S_{0}$ of the $T(6-4) T$. The lowest singlet state $\mathrm{S}_{1}$ possesses a considerably longer $\mathrm{C}^{\prime}=\mathrm{O}$ double bond $(1.345 \AA)$, which is assigned to an $n \rightarrow \pi^{*}$ state character as $S_{n}$. The $S_{2}$ state is a $\pi \rightarrow \pi^{*}$ excitation mainly localized in the pyrimidone ring and noted as $S_{\mathrm{pi}}$. With respect to the $\mathrm{S}_{0}$ zerolevel point, the relative energies for the $\mathrm{n} \rightarrow \pi^{*}\left(\mathrm{~S}_{1}\right)$ and $\pi \rightarrow \pi^{*}$ $\left(\mathrm{S}_{2}\right)$ states in the (6-4) PP are 3.2 and $3.6 \mathrm{eV}$, respectively. Along the ground-state reaction coordinate, a transition state marked as $\mathrm{S}_{0}$-TS has been located by the CAS $(10,8)$ optimization, which is responsible for the $\mathrm{N}^{\prime}-\mathrm{C}^{\prime}$ bond cleavage with a barrier of $3.7 \mathrm{eV}$.

The ground-state $\mathrm{S}_{0}$ of the $\mathrm{T}(\mathrm{dew}) \mathrm{T}$ is thermodynamically unstable by $2.3 \mathrm{eV}$ in comparison with the $\mathrm{T}(6-4) \mathrm{T}$. The $\mathrm{N} 3^{\prime}-\mathrm{C} 6^{\prime}$ bond length is $1.490 \AA$ in the $\mathrm{S}_{0}$ state, implying that the pyrimidone ring has converted to the Dewar benzene. Compared with the ground state, the $\mathrm{C}^{\prime}-\mathrm{C} 5^{\prime}$ bond of $\mathrm{T}_{1}$ is $1.549 \AA$, which is much longer than the $\mathrm{S}_{0}$ state $(1.346 \AA)$. The calculated low-lying singlet excited states of the $\mathrm{T}(\mathrm{dew}) \mathrm{T}$ are all $n \rightarrow \pi^{*}$ transitions. The $S_{1}$ state is ${ }^{1} n \pi^{*}$ state localized in the pyrimidine ring of the $T($ dew $) T$. The $S_{2}$ state is the $n \rightarrow \pi^{*}$ transition centered at $\mathrm{C}^{\prime}=\mathrm{O}$ of the Dewar benzene ring, which corresponds to the $S_{n}$ state of the T(6-4)T noted above. As listed in Table 1, the adiabatic excitation energies from the $S_{0}$ to the $S_{1}$ state and the $S_{2}$ state are predicted to be 4.2 and 4.6 $\mathrm{eV}$, respectively.

It is known that the surface intersection plays an important role in the photodissociation dynamics of a molecule and the ultrafast passage between electronic states is often through conical intersections (CIs). ${ }^{34}$ For the $\mathrm{T}(6-4) \mathrm{T}$, the $\mathrm{S}_{0}$ and the $\mathrm{T}_{1}$ crossing $\left(\mathrm{S}_{0} / \mathrm{T}_{1}\right)$ and the $\mathrm{S}_{0}$ and the $\mathrm{S}_{2}$ crossing $\left(\mathrm{S}_{0} / \mathrm{S}_{2}\right)$ are quite similar in structure but differ in energy. The structures of the pyrimidine ring in these two CIs are similar to that in the ground state, whereas the pyrimidone ring is indistinguishable. First, the $\mathrm{C}^{\prime}-\mathrm{C} 3^{\prime}$ bond lengths in the $\mathrm{S}_{0} / \mathrm{S}_{2}$ and the $\mathrm{S}_{0} / \mathrm{T}_{1}$ are nearly equal with a value of $\sim 1.414 \AA$, longer than that $(1.272$ $\AA$ ) in the ground state. Second, the N3'-C6' bond length is decreased to $\sim 2.535 \AA$ in the CIs. All of these cause out-ofplane deformation of the pyrimidone. It was found that CIs of pyrimidine bases often have out-of-plane deformations with twisted double-bond C5-C6. ${ }^{34}$ These CIs are responsible for the key deactivation step of the nucleobases. As shown in Table 1 , the CIs have a relative energy of $3.1 \mathrm{eV}$ for the $S_{0} / T_{1}$ and 


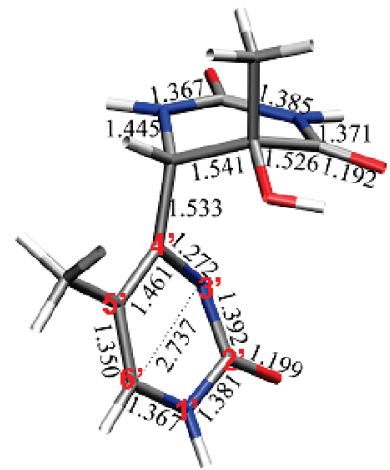

$\mathrm{S}_{0}$

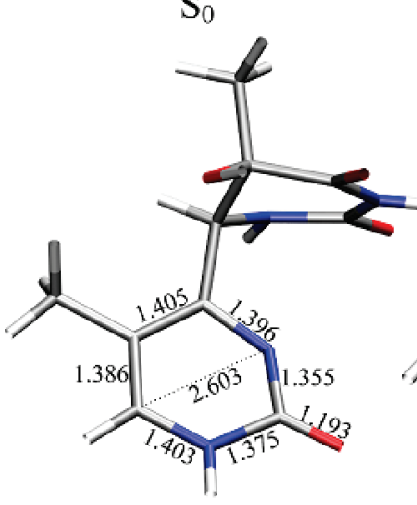

$\mathrm{S}_{2}$

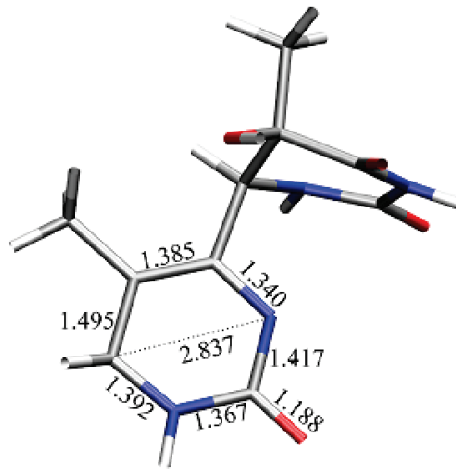

$\mathrm{T}_{1}$

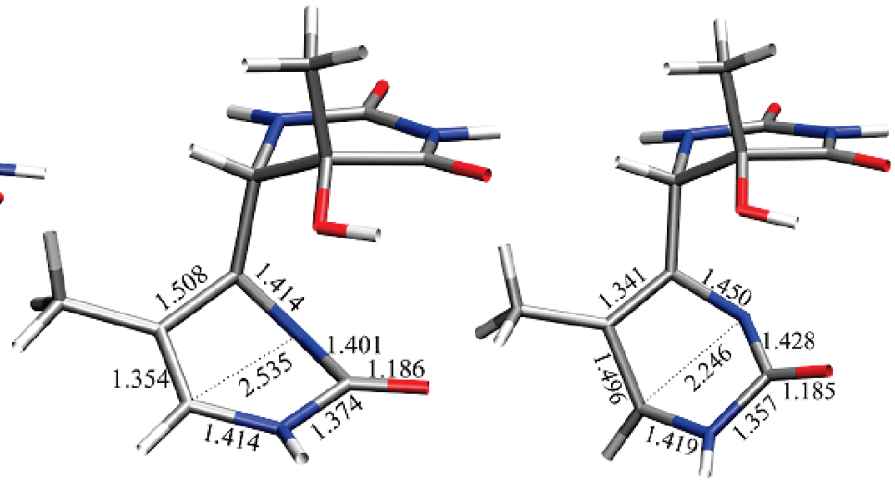

$\mathrm{S}_{0} / \mathrm{S}_{2}$

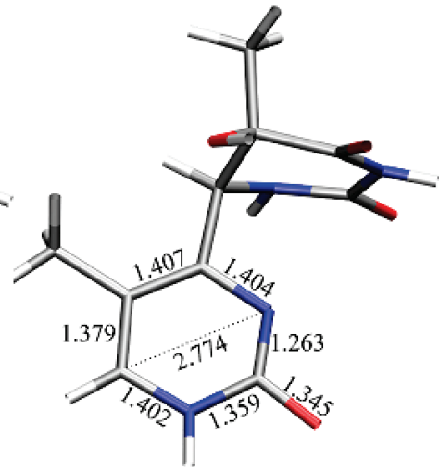

$\mathrm{S}_{1}$

$\mathrm{S}_{0}$-TS

Figure 2. Optimized geometries at the CAS(10,8)/6-31G(d) level for the (6-4) PP in the ground and excited states and also the conical intersections (CIs). Selected bond lengths are shown in angstroms.

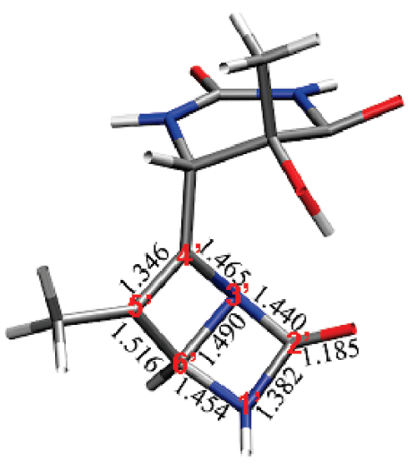

$\mathrm{S}_{0}$

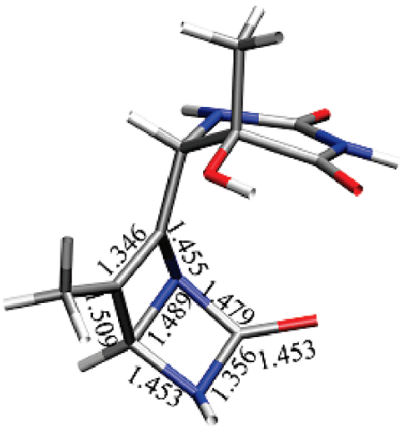

$\mathrm{S}_{2} / \mathrm{T}_{1}$

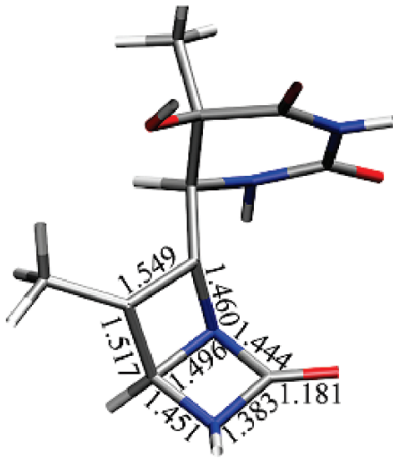

$\mathrm{T}_{1}$

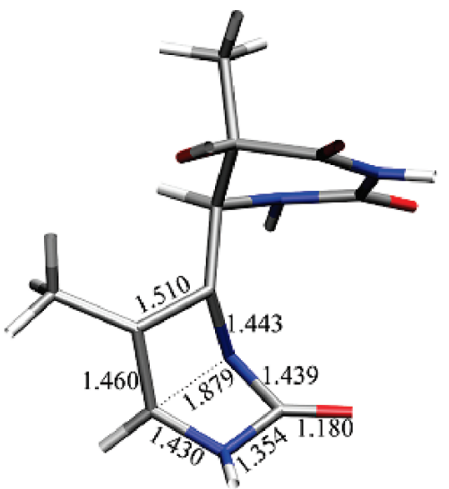

$\mathrm{T}_{1}$-TS

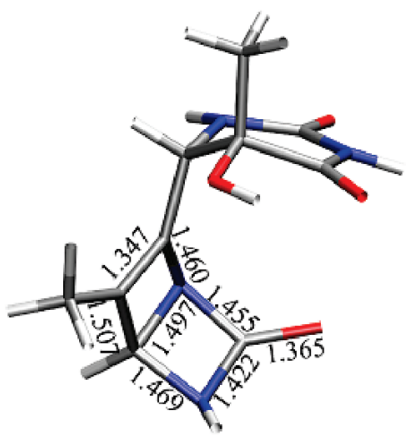

$\mathrm{S}_{2}$

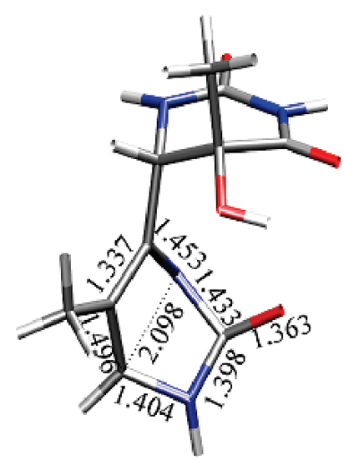

$\mathrm{S}_{2}$-TS

Figure 3. Optimized geometries at the CAS(10,8)/6-31G(d) level for the Dewar PP in the ground and excited states and also the conical intersections (CIs). Selected bond lengths are shown in angstroms.

$3.9 \mathrm{eV}$ for the $\mathrm{S}_{0} / \mathrm{S}_{2}$. Moreover, we also found two other intersection points, which are the $S_{1} / T_{1}$ and the $S_{0} / S_{1}$ with relative higher energies (Table 1). For the $\mathrm{T}(\mathrm{dew}) \mathrm{T}$, the $\mathrm{S}_{\mathrm{n}}$ and $T_{1}$ crossing point $S_{n} / T_{1}$ has a relative energy of $5.1 \mathrm{eV}$. The 
TABLE 1: Calculated Relative Energies for the (6-4) PP and the Dewar PP in the Ground and Excited States at the CASPT2/6-31G(d) Level Based on the Optimized Structures at the CASSCF $(10,8) / 6-31 G(d)$ in the Gas Phase

\begin{tabular}{lc}
\hline \multicolumn{2}{c}{ energy $(\mathrm{eV})$} \\
\cline { 2 - 2 } $6-4 \mathrm{PP}$ & CASPT2 $(\mathrm{eV})$ \\
\hline $\mathrm{S}_{0}$ & 0.0 \\
$\mathrm{~T}_{1}$ & 2.9 \\
$\mathrm{~S}_{1}\left(\mathrm{~S}_{\mathrm{n}}\right)$ & 3.2 \\
$\mathrm{~S}_{2}\left(\mathrm{~S}_{\mathrm{pi}}\right)$ & 3.6 \\
$\mathrm{~S}_{0} \mathrm{~S}_{2}$ & 3.9 \\
$\mathrm{~S}_{0} \mathrm{~S}_{1}$ & 4.4 \\
$\mathrm{~S}_{0} \mathrm{~T}_{1}$ & 3.1 \\
$\mathrm{~S}_{1} \mathrm{~T}_{1}$ & 3.9 \\
$\mathrm{~S}_{0}-\mathrm{TS}$ & 3.7 \\
$\mathrm{Dewar}$ & $\mathrm{CASPT}(\mathrm{eV})$ \\
\hline $\mathrm{S}_{0}$ & 0.0 \\
$\mathrm{~T}_{1}$ & 3.0 \\
$\mathrm{~S}_{1}$ & 4.2 \\
$\mathrm{~S}_{2}\left(\mathrm{~S}_{\mathrm{n}}\right)$ & 4.6 \\
$\mathrm{~S}_{0} \mathrm{~T}_{1}$ & 4.1 \\
$\mathrm{~S}_{\mathrm{n}} \mathrm{T}_{1}$ & 5.1 \\
$\mathrm{~S}_{0} \mathrm{~S}_{1}$ & 5.4 \\
$\mathrm{~T}_{1}-\mathrm{TS}$ & 3.1 \\
$\mathrm{~S}_{\mathrm{n}}-\mathrm{TS}$ & 5.6
\end{tabular}

optimized structure is shown in Figure 3. In addition, the $\mathrm{S}_{0} / \mathrm{S}_{1}$ and the $S_{0} / T_{1}$ CIs were also found. However, the $S_{1} \rightarrow S_{0}$ process is difficult to take place for the $\mathrm{T}(\mathrm{dew}) \mathrm{T}$ because of the large change in the structure and high energy of CI.

We have collected the potential energy surfaces for isomerization between the $\mathrm{T}(6-4) \mathrm{T}$ and the $\mathrm{T}(\mathrm{dew}) \mathrm{T}$ in Figure 5. It can be seen that upon the UV excitation at 313-280 nm, the $\mathrm{T}(6-4) \mathrm{T}$ is first excited to its excited singlet $\pi \rightarrow \pi^{*}\left(\mathrm{~S}_{\mathrm{pi}}\right)$ state. Near the $S_{p i}$ minimum, a crossing of the $S_{p i}$ and the $S_{0}$ takes place, which is marked as $S_{0} / S_{p i}$. From the minimum of the $S_{p i}$ state, the $\mathrm{T}(6-4) \mathrm{T}$ molecule goes along the potential energy surface of the $S_{\mathrm{pi}}$ to reach the $\mathrm{S}_{0} / \mathrm{S}_{\mathrm{pi}} \mathrm{CI}$, where the photoexcited system can decay nonradiatively to the $\mathrm{S}_{0}$. However, it is noticed that the $\mathrm{CI} \mathrm{S}_{0} / \mathrm{S}_{\mathrm{pi}}$ is only $0.2 \mathrm{eV}$ higher than the $\mathrm{S}_{0}$-TS in energy. The molecule can probably relax to the ground-state potential energy surface through the $\mathrm{S}_{0}$-TS. In this case, the photoisomerization of the $\mathrm{T}(6-4) \mathrm{T}$ toward the product $\mathrm{T}(\mathrm{dew}) \mathrm{T}$ is thus controlled by the ground-state potential; see the red arrows in Figure 5. It clearly illustrates that the CI plays an important

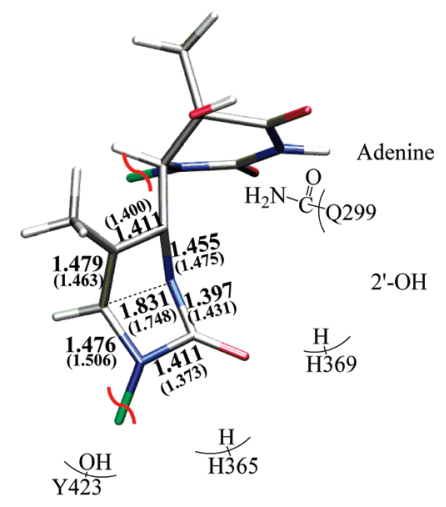

$\mathrm{T}($ dew $) \mathrm{T}-\mathrm{TS}$

Figure 4. Optimized geometrical parameters of the models M-2 and M-1 (in parentheses) at the UB3LYP/6-31G(d) level for the radical anion in the photolyase.

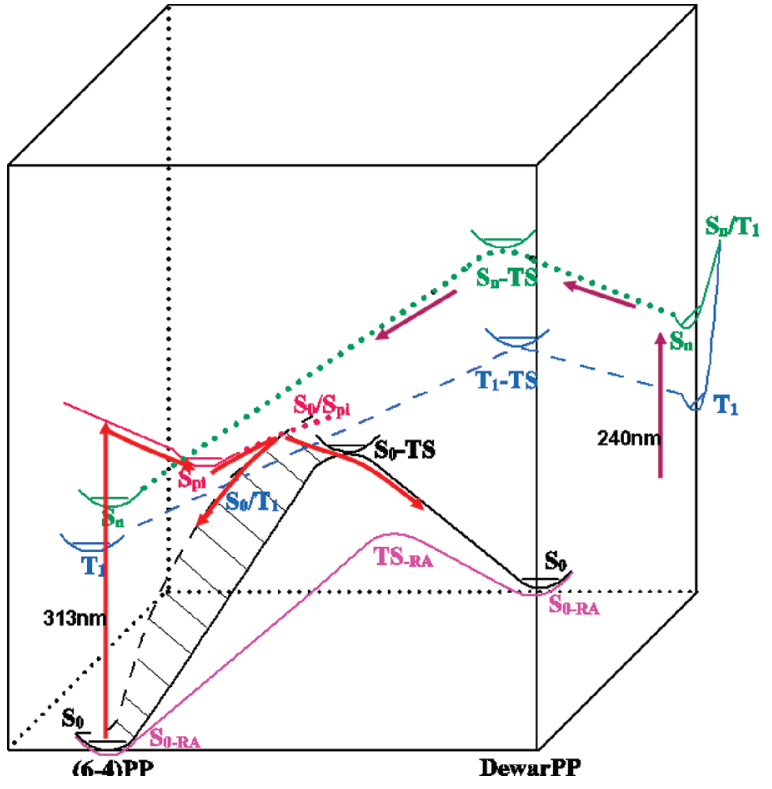

Figure 5. Calculated potential energy surfaces and suggested mechanism for the UV photoinduced isomerization between the (6-4) PP and the Dewar PP. The ground state is denoted by the black line. Moreover, the lowest triplet state $T_{1}$ and singlet ${ }^{1} n \pi^{*}$ state $S_{n}$ are shown in blue and green lines. Radical anion (RA) pathway is shown in magenta. The red and purple arrow lines show the possible isomerization mechanism between the (6-4) PP and the Dewar PP.

role in the formation of the Dewar PP. Once the Dewar PP is formed, it may persist in vivo for a long time unless it can be repaired by enzyme, or it will turn back to the (6-4) PP upon the excitation by a UV-C light. The reversed isomerization involves in the ring-opening process of the Dewar benzene. Dewar benzenes are highly strained valence isomers of benzenes that have been studied in detail for many years. ${ }^{35-37}$ The isomerization of the Dewar benzene to benzene is $3.7 \mathrm{eV}$ exothermic reaction. ${ }^{35}$ Although the isomerization of the Dewar benzene to benzene has been studied extensively, to the best of our knowledge, the photoisomerization of the Dewar PP to the (6-4) PP has not yet been explored theoretically. As presented in Figure 5, after the excitation of 260-240 nm UV-C light, the $T\left(\right.$ dew)T molecule is relaxed to the ${ }^{1} n \pi^{*}$ excited state $S_{n}$, which has relative energy of $4.6 \mathrm{eV}$ above the ground state. The ${ }^{1} \mathrm{n} \pi^{*}$ state is usually called a "dark" excited state compared with the "bright" ${ }^{1} \pi \pi^{*}$ states. It was reviewed that in the water solution, $10-50 \%$ of pyrimidine bases decay via a ${ }^{1} \mathrm{n} \pi^{*}$ state after photoexcitation..$^{38} \mathrm{~A}$ transition state $\mathrm{S}_{\mathrm{n}}$-TS was found on the $S_{n}$ pathway. Nevertheless, the $S_{n}$-TS lies $1 \mathrm{eV}$ above the $S_{n}$ state of the T(dew)T. It means in the gas phase, the Dewar PP molecule may not have sufficient energies left to overcome the barrier of the $\mathrm{N}^{\prime}-\mathrm{C} 6^{\prime}$ bond cleavage along the $\mathrm{S}_{\mathrm{n}}$ pathway. If the photoexcited molecule can reach the $S_{n}$ and $T_{1}$ crossing point $S_{\mathrm{n}} / T_{1}$, then the reaction will take place along the $T_{1}$ potential surface. The search for the TS of the $\mathrm{N}^{\prime}-\mathrm{C}^{\prime}$ bond cleavage on the $T_{1}$ surface gives the $T_{1}$-TS structure in Figure 3. Then, the photolesion can relax to the ground state of the $(6-4) \mathrm{PP}$ following intersystem crossing (ISC) between the $T_{1}$ and the $\mathrm{S}_{0}$ states.

Solvation Effect on the Photoinduced Isomerization between the (6-4) PP and the Dewar PP. In a real biological environment, the DNA molecule is surrounded by an aqueous environment. The impact of the solution on the relaxation pathway in the water solution needs to be examined. On the basis of the results in the gas phase, a water-box surrounding the target molecule was set to mimic the aqueous environment. 
TABLE 2: Calculated Relative Energies for the (6-4) PP and the Dewar PP in the Ground and Excited States with the CASPT2//CASSCF/Amber (QM/MM) Protocol in the Solution

\begin{tabular}{lc}
\hline $6-4$ PP & QM/MM solvent box $(\mathrm{eV})$ \\
\hline $\mathrm{S}_{0}$ & 0.0 \\
$\mathrm{~S}_{\mathrm{n}}$ & 3.4 \\
$\mathrm{~S}_{\mathrm{pi}}$ & 3.6 \\
$\mathrm{~S}_{0} \mathrm{~S}_{\mathrm{pi}}$ & 3.8 \\
$\mathrm{~S}_{0}-\mathrm{TS}$ & 3.3 \\
\hline Dewar & QM/MM solvent box $(\mathrm{eV})$ \\
\hline $\mathrm{S}_{0}$ & 0.0 \\
$\mathrm{~T}_{1}$ & 2.8 \\
$\mathrm{~S}_{\mathrm{n}}$ & 4.2 \\
$\mathrm{~S}_{\mathrm{n}} \mathrm{T}_{1}$ & 4.6 \\
$\mathrm{~T}_{1}-\mathrm{TS}$ & 3.1 \\
$\mathrm{~S}_{\mathrm{n}}-\mathrm{TS}$ & 4.8 \\
\end{tabular}

The summarized energies of some key points with CASPT2// CASSCF/Amber (QM/MM) method are listed in Table 2.

The corresponding isomerization reactions are retained with respect to the gas phase; that is, the formation of the Dewar PP is mainly controlled by the crossing between the "bright" ${ }^{1} \pi \pi^{*}$ state and the ground state of the $(6-4)$ PP. However, when the DNA molecule is put in the solution, the solvent may stabilize the molecule through the intermolecular hydrogen bonding. As shown in Table 2, when the solvent effect is included, the barriers for the $\mathrm{N}^{\prime}-\mathrm{C}^{\prime}$ bond cleavage on the $\mathrm{S}_{0}$ and $\mathrm{S}_{\mathrm{n}}$ surfaces are significantly decreased. For instance, the barrier for the $\mathrm{N} 3^{\prime}-\mathrm{C}^{\prime}$ bond cleavage on the $\mathrm{S}_{\mathrm{n}}$ is $0.6 \mathrm{eV}$ in the aqueous solution but $1 \mathrm{eV}$ in the gas phase. It is then energetically accessible for the isomerization from the $\mathrm{T}(\mathrm{dew}) \mathrm{T}$ to the $\mathrm{T}(6-4) \mathrm{T}$ through the "dark" ${ }^{1} \mathrm{n} \pi^{*}$ state $\mathrm{S}_{\mathrm{n}}$ in the aqueous solution, which was considered to be an issue for the nonradiative deactivation in various studies. ${ }^{38}$

Meanwhile, the relative energy of the $S_{n} / T_{1}$ is significantly reduced to $4.6 \mathrm{eV}$ in the solution. Therefore, upon the excitation at $240 \mathrm{~nm}$, the Dewar PP molecule may decay to the $T_{1}$ state through the ISC from the $S_{n}$ state. The $T_{1}$ state is also considered to be a "dark" state like the ${ }^{1} \mathrm{n} \pi *$ state previously mentioned. Because of the low triplet yields, ISC dynamics is normally difficult to observe in the aqueous solution. However, there are now more and more studies that show that efficient ISC involved with the "dark" triplet state can play an important role in the deactivation passage. ${ }^{34}$ The corresponding barrier of the N3'-C6' bond cleavage reaction in the $T_{1}$ state is found to be only 0.3 $\mathrm{eV}$. From an energetic viewpoint, the bond cleavage reaction in the $\mathrm{T}_{1}$ state is also a possible candidate for the reversed isomerization process in the aqueous solution.

In a word, the solvent effect has great impact on the reaction barrier of the isomerization process. In the aqueous solution, the barrier of $\mathrm{N}^{\prime}-\mathrm{C}^{\prime}$ bond cleavage reaction is significantly lowered by the solvent. The direct results of this solvent effect are that two channels involving the "dark" excited states, which are the ${ }^{1} n \pi^{*}$ state and the $T_{1}$ state, have been identified to be efficient pathways for the isomerization in the aqueous solution.

Conversion of the Dewar Valence Isomers into the Corresponding (6-4) Photoproducts in the (6-4) Photolyase. Different from the gas phase and the solution, in organisms, the (6-4) PP and the Dewar PP photolesions can be repaired by flavoproteins. ${ }^{2}$ The photolyase is one of flavoproteins that can bind to the site of lesions and use the UV light energy to split the photodamaged lesions via the redoxcyclic of a flavin cofactor. There is electron transfer from the
TABLE 3: Calculated Relative Energies for the (6-4) PP and the Dewar PP in the Ground State via the Neutral and Radical Anion (RA) Pathway at the B3LYP and the UB3LYP/6-31G(d) Level in the Protein

\begin{tabular}{lccc}
\hline & M-1 (relative energy/eV) & & M-2 (relative energy/eV) \\
\cline { 2 - 2 } TpT & solvent box & & PCM \\
\hline T(6-4)T & 0.0 & 0.0 \\
TS & 4.0 & & 4.3 \\
T(dew)T & 2.6 & 3.1 \\
T(6-4)T-(RA) & 0.0 & 0.0 \\
TS-RA & 3.5 & & 4.5 \\
T(dew)T-(RA) & 2.7 & 3.8
\end{tabular}

cofactor to the lesion in the photolyase. In addition to the abovediscussed isomerization pathway, new channels might open in the protein environment and result in important effects on the photorepair process of these two lesions. Recent experimental data indicated that the repair of the Dewar isomers by the (6-4) photolyase could be involved in the electron injection process, which rearranges the Dewar lesions into the corresponding $(6-4)$ lesions. $^{16}$ It is thus interesting to examine such a hypothesis from theoretical calculations.

Our calculations on the M-1 for the T(6-4)T have shown that the TS along the ground state potential is almost $1.4 \mathrm{eV}$ higher than the $\mathrm{T}(\mathrm{dew}) \mathrm{T}$ in energy, which makes the rearrangement from the neutral $\mathrm{T}(\mathrm{dew}) \mathrm{T}$ to the $\mathrm{T}(6-4) \mathrm{T}$ almost impossible in the ground state (Table 3). However, if one electron is injected to form RA, then the barrier is sharply decreased to $0.8 \mathrm{eV}$ in the solvent box. A TS with $\mathrm{C}-\mathrm{N}$ bond of $1.748 \AA$ is found, as shown in Figure 4. In the large model M-2, key surrounding residues as employed in recent experimental studies on the (6-4) photolyase ${ }^{16,39,40}$ are included. The first residue Q299 is chosen for the formation of the hydrogen bonds between $\mathrm{N} 3$ and O2. The inclusion of the triad consisting of His365His369-Tyr423 is due to its importance for catalysis. ${ }^{40}$ The flavin adenine nucleotide (FAD) cofactor, which is in close proximity to the photoproduct, is simplified by its adenine part and $2^{\prime}$ $\mathrm{OH}$ group. The former acts as an electron injection group, and the latter can form a hydrogen bond with the His365. The geometry was then optimized to get the radical-anion equilibrium and transition structures for the $\mathrm{T}(\mathrm{dew}) \mathrm{T}$ in the photolyase. It is found that the vertical electron affinity (EA) of the M-2 model for the $\mathrm{T}(\mathrm{dew}) \mathrm{T}$ is $-0.3 \mathrm{eV}$, but the adiabatic EA is 0.8 $\mathrm{eV}$. The large EA value indicates that the T(dew)T RA can be stable in the photolyase. Along the reaction pathway, the RA TS for rearrangement from the $\mathrm{T}(\mathrm{dew}) \mathrm{T}$ to the $\mathrm{T}(6-4) \mathrm{T}$ is located at the $\mathrm{C}-\mathrm{N}$ bond length of $1.831 \AA$. The reaction energy barrier is $0.7 \mathrm{eV}$ if the solvent effect is considered by the PCM model. In agreement with the results from the M-1 model, the reaction barrier of the neutral M-2 model is nearly $1.2 \mathrm{eV}$ high for the $\mathrm{T}(\mathrm{dew}) \mathrm{T}$. Compared with these two models, we can conclude that the M-1 is a reasonable model to describe the photochemical properties of DNA lesions, and the protein environment in the M-2 model has an important impact on the reaction barrier that cannot be ignored. Besides, the remarkable differences in the isomerization barrier between the neutral and anion states may significantly change the photorepair process in the $(6-4)$ photolyase. A common enzymatic repair pathway involving an oxetane intermediate of the CPDs and the (6-4) PP was convincingly suggested from both theoretical and experimental studies. ${ }^{41}$ Nonetheless, this was recently questioned by Domratcheva et al., who proposed a nonoxetane repair mechanism. ${ }^{42}$ Very recently, Zhong's group performed the ultrafast spectroscopic studies and found that the proton transfer 
process from the His 364 to the $6-4 \mathrm{PP}^{\bullet^{-}}$in the anionic ground state is the key step of the repair mechanism. ${ }^{43}$ However, for the photorepair process of the Dewar PP, the corresponding mechanism is virtually unknown. It can be seen from our results that the electron injection from the protein may open a new channel for the isomerization from the Dewar PP to the (6-4) $\mathrm{PP}$, and this may directly influence the photorepair mechanism of the Dewar PP. More work along this line is underway in our laboratory.

\section{Conclusions}

In summary, we have investigated the photoinduced isomerization mechanism between two DNA photoproducts: the (6-4) PP and the Dewar PP, from ab initio calculations. Geometries and electronic structures of the ground, excited, and related crossing points of these two different lesions have been obtained by the CASSCF method. A solution matrix is used to mimic the aqueous environment with CASPT2//CASSCF/Amber (QM/ $\mathrm{MM})$ method. Our calculations have revealed the mechanism for the UV photoinduced isomerization between the Dewar PP and the (6-4) PP. It is found that the excitation with $313 \mathrm{~nm}$ UV light on the (6-4) PP initiates the relaxation along the $S_{\mathrm{pi}}$ $\left({ }^{1} \pi \pi^{*}\right)$ state via the CI $\left(\mathrm{S}_{0} / \mathrm{S}_{\mathrm{pi}}\right)$ to the ground-state potential energy surface of the Dewar PP via the $\mathrm{S}_{0}$-TS. Meanwhile, there are two different decay channels to account for the opposite isomerization. When the Dewar PP absorbs the UV light around $240 \mathrm{~nm}$, the relaxation pathway occurs mainly on the ${ }^{1} \mathrm{n} \pi *$ state $\mathrm{S}_{\mathrm{n}}$. With enough remaining energy, it needs to overcome the barrier of the $S_{n}$-TS to reach to the low-lying excited state of the $(6-4)$ PP. In the gas phase, the barrier is too high to pass. However, in the solution matrix, the solvent molecules stabilize the TS and lower the barrier to open up this decay channel. Moreover, the decay along the $\mathrm{T}_{1}$ state is also an alternative pathway for an efficient ISC from the $S_{n}$ state. In the (6-4) photolyase, the rearrangement of the Dewar lesions into the corresponding (6-4) lesions with electron injection was presented as an efficient repair pathway, supporting the hypothesis from the experiments. ${ }^{16}$

Acknowledgment. The work was supported by the Swedish National Infrastructure for Computing (SNIC), the NSFC (20720102038, 20925311), and the Major State Basic Research Development Programs (2004CB719903, 2010CB923300) of China.

Supporting Information Available: Structural parameters for the M-1 model and selected structural coordinates for the M-2 model. This material is available free of charge via the Internet at http://pubs.acs.org.

\section{References and Notes}

(1) Donovan, P.; Perrett, C. M.; Zhang, X. H.; Montaner, B.; Xu, Y. Z.; Harwood, C. A.; McGregor, J. M.; Walker, S. L.; Hanaoka, F.; Karran, P. Science 2005, 309, 1871-1874.

(2) Sancar, A. Chem. Rev. 2003, 103, 2203-2237.

(3) Sinha, R. P.; Hader, D. P. Photochem. Photobiol. Sci. 2002, 1, $225-$ 236

(4) Batista, L. F. Z.; Kaina, B.; Meneghini, R.; Menck, C. F. M. Mutat. Res., Rev. Mutat. Res. 2009, 681, 197-208.

(5) Woodhead, A. D.; Setlow, R. B.; Tanaka, M. J. Epidemiol. 1999, 9, S102-S114.

(6) Claerhout, S.; Van Laethem, A.; Agostinis, P.; Garmyn, M. Photochem. Photobiol. 2006, 5, 199-207.

(7) (a) Beukers, R.; Eker, A. P. M.; Lohman, P. H. M. DNA Repair 2008, 7, 530-543. (b) Law, Y. K.; Azadi, J.; Crespo-Hernandez, C. E.; Olmon, E.; Kohler, B. Biophys. J. 2008, 94, 3590-3600. (c) Hariharan, M.; Lewis, F. D. J. Am. Chem. Soc. 2008, 130, 11870-11871. (d) McCullagh, M.; Hariharan, M.; Lewis, F. D.; Markovitsi, M.; Douki, T.;
Schatz, G. C. J. Phys. Chem. B 2010, 114, 5215-5221. (e) Mouret, S.; Philippe, C.; Gracia-Chantegrel, J.; Banyasz, A.; Karpati, S.; Markovitsi, D.; Douki, T. Org.Biomol. Chem. 2010, 8, 1706-1711.

(8) de Lima-Bessa, K. M.; Armelini, M. G.; Chigancas, V.; Jacysyn, J. F.; Amarante-Mendes, G. P.; Sarasin, A.; Menck, C. F. M. DNA Repair 2008, 7, 303-312. 2835

(9) Taylor, J. S.; Cohrs, M. P. J. Am. Chem. Soc. 1987, 109, 2834-

(10) Mitchell, D. L. Photochem. Photobiol. 1988, 48, 51-57.

(11) Mouret, S.; Baudouin, C.; Charveron, M.; Favier, A.; Cadet, J.; Douki, T. Proc. Natl. Acad. Sci. U.S.A. 2006, 103, 13765-13770.

(12) Nakajima, S.; Lan, L.; Kanno, S.; Takao, M.; Yamamoto, K.; Eker, A. P.; Yasui, A. J. Biol. Chem. 2004, 279, 46674-46677.

(13) (a) Beukers, R.; Berends, W. Biochim. Biophys. Acta 1960, 41, 550-551. (b) Rahn, R. O.; Hosszu, J. L. Photochem. Photobiol. 1969, 10, 131-137. (c) Heelis, P. F.; Liu, S. B. J. Am. Chem. Soc. 1997, 119, 29362937.

(14) Johns, H. E.; Pearson, M. L.; LeBlanc, J. C.; Helleiner, C. W. J. Mol. Biol. 1964, 9, 503-524.

(15) Perdiz, D.; Grof, P.; Mezzina, M.; Nikaido, O.; Moustacchi, E.; Sage, E. J. Biol. Chem. 2000, 275, 26732-26742.

(16) Glas, A. F.; Kaya, E.; Schneider, S.; Heil, K.; Fazio, D.; Maul, M. J.; Carell, T. J. Am. Chem. Soc. 2010, 132, 3254-3255.

(17) Lee, J. H.; Hwang, G. S.; Choi, B. S. Proc. Natl. Acad. Sci. U.S.A. 1999, 96, 6632-6636.

(18) Case, D. A.; Pearlman, D. A.; Caldwell, J. W.; Cheatham, T. E., III; Ross, W. S.; Simmerling, C. L.; Darden, T. A.; Merz, K. J.; Stanton, R. V.; Cheng, A. L.; Vincent, J. J.; Crowley, M.; Tsui, V.; Radmer, R. J.; Duan, Y.; Pitera, J.; Massova, I.; Seibel, G. L.; Singh, U. C.; Weiner, P. K.; Kollman., P. A. AMBER 6; University of California: San Francisco, 1999.

(19) Cossi, M.; Scalmani, G.; Rega, N.; Barone, V. J. Chem. Phys. 2002, $117,43-54$.

(20) Cossi, M.; Rega, N.; Scalmani, G.; Barone, V. J. Comput. Chem. 2003, 24, 669-681.

(21) Cossi, M.; Barone, V.; Robb, M. A. J. Chem. Phys. 1999, 111, $5295-5302$.

(22) Himo, F.; Siegbahn, P. E. M. Chem. Rev. 2003, 103, 2421-2456. (23) Noodleman, L.; Lovell, T.; Han, W.-G.; Li, J.; Himo, F. Chem. Rev. 2004, 104, 459-508.

(24) Siegbahn, P. E. M.; Borowski, T. Acc. Chem. Res. 2006, 39, 729738.

(25) Himo, F. Theor. Chem. Acc. 2006, 116, 232-240. 68.

(27) Himo, F.; Siegbahn, P. E. M. J. Biol. Inorg. Chem. 2009, 14, 643651.

(28) Blomberg, M. R. A.; Siegbahn, P. E. M. Biochim. Biophys. Acta 2010, 1797, 129-142.

(29) Frisch, M. J.; Trucks, G. W.; Schlegel, H. B.; Scuseria, G. E.; Robb, M. A.; Cheeseman, J. R.; Montgomery, J. A., Jr.; Vreven, T.; Kudin, K. N.; Burant, J. C.; Millam, J. M.; Iyengar, S. S.; Tomasi, J.; Barone, V.; Mennucci, B.; Cossi, M.; Scalmani, G.; Rega, N.; Petersson, G. A.; Nakatsuji, H.; Hada, M.; Ehara, M.; Toyota, K.; Fukuda, R.; Hasegawa, J.; Ishida, M.; Nakajima, T.; Honda, Y.; Kitao, O.; Nakai, H.; Klene, M.; Li, X.; Knox, J. E.; Hratchian, H. P.; Cross, J. B.; Adamo, C.; Jaramillo, J.; Gomperts, R.; Stratmann, R. E.; Yazyev, O.; Austin, A. J.; Cammi, R.; Pomelli, C.; Ochterski, J. W.; Ayala, P. Y.; Morokuma, K.; Voth, G. A.; Salvador, P.; Dannenberg, J. J.; Zakrzewski, V. G.; Dapprich, S.; Daniels, A. D.; Strain, M. C.; Farkas, O.; Malick, D. K.; Rabuck, A. D.; Raghavachari, K.; Foresman, J. B.; Ortiz, J. V.; Cui, Q.; Baboul, A. G.; Clifford, S.; Cioslowski, J.; Stefanov, B. B.; Liu, G.; Liashenko, A.; Piskorz, P.; Komaromi, I.; Martin, R. L.; Fox, D. J.; Keith, T.; Al-Laham, M. A.; Peng, C. Y.; Nanayakkara, A.; Challacombe, M.; Gill, P. M. W.; Johnson, B.; Chen, W.; Wong, M. W.; Gonzalez, C.; Pople, J. A. Gaussian03, revision C.02; Gaussian, Inc.: Pittsburgh, PA, 2004.

(30) Andersson, K. MOLCAS, revision 7.1; University of Lund: Lund, Sweden, 2007.

(31) Ponder, J.; Richards, W. F. M. J. Comput. Chem. 1987, 8, 10161024.

(32) Ferré, N.; Cembran, A.; Garavelli, M.; Olivucci, M. Theor. Chem. Acc. 2004, 112, 335-341.

(33) Humphrey, W.; Dalke, A.; Schulten, K. J. Mol. Graphics 1996, 14, 33-38.

(34) Middleton, C. T.; de La Harpe, K.; Su, C.; Law, Y. K.; CrespoHernández, C. E.; Kohler, B. Аnnu. Rev. Phys. Chem. 2009, 60, 217-239.

(35) Norton, J. E.; Olson, L. P.; Houk, K. N. J. Am. Chem. Soc. 2006, $128,7835-7845$.

(36) Bally, T.; Matzinger, S.; Bednarek, P. J. Am. Chem. Soc. 2006, $128,7828-7834$

(37) Feffar, L.; Mis, M.; Dinnocenzo, J. P.; Farid, S.; Merkel, P. B.; Robello, D. R. J. Org. Chem. 2008, 73, 5683-5692. 
(38) Hare, P. M.; Crespo-Hernández, C. E.; Kohler, B. Proc. Natl. Acad. Sci. U.S.A. 2007, 104, 435-440.

(39) Glas, A. F.; Schneider, S.; Maul, M. J.; Hennecke, U.; Carell, T. Chem.-Eur. J. 2009, 15, 10387-10396.

(40) Maul, M. J.; Barends, T. R.; Glas, A. F.; Cryle, M. J.; Domratcheva, T.; Schneider, S.; Schlichting, I.; Carell, T. Angew. Chem., Int. Ed. 2008, 47, 10076-10080.

(41) (a) Kim, S. T.; Malhotra, K.; Smith, C. A.; Taylor, J. S.; Sancar, A. J. Biol. Chem. 1994, 269, 8535-8540. (b) Zhao, X.; Liu, J.; Hsu, D. S.;
Zhao, S.; Taylor, J. S.; Sancar, A. J. Biol. Chem. 1997, 272, 32580-32590. (c) Wang, Y.; Gaspar, P. P.; Taylor, J. S. J. Am. Chem. Soc. 2000, 122, $5510-5519$.

(42) Domratcheva, T.; Schlichting, I. J. Am. Chem. Soc. 2009, 131, 17793-17799.

(43) Li, J.; Liu, Z. Y.; Tan, C. T.; Guo, X. M.; Wang, L. J.; Sancar, A.; Zhong, D. P. Nature 2010, 466, 887-890.

JP107873W 